the findings of interstitial fibrosis, disrupted thyroid follicles, and Hürthle cells were not consistent with euthyroid Graves' disease, medically treated Graves' disease, or Hashitoxicosis, because of the lack of classic ophthalmopathy, the replacement of normal thyroid follicular epithelium by hyperplastic epithelium in less than $50 \%$ of the specimen, and the euthyroid state in this patient. ${ }^{70}$ Painless thyroiditis, also known as silent thyroiditis, is another possibility; this is characterised by a painless thyroid gland, raised serum concentrations of thyroid hormone, low radioactive iodine uptake, and spontaneously resolving hyperthyroidism. ${ }^{10}$ Histologically, painless thyroiditis resembles autoimmune thyroiditis, but according to Mizukami et $a l^{10}$ stromal fibrosis and Hürthle cells are rare in the former. After contacting the patient's clinician, we found that she had been receiving long term lithium treatment (over five years) for her psychiatric condition, and we were then able to arrive at the diagnosis of lithium associated autoimmune thyroiditis. However, without knowledge of the patient's clinical history, it probably would have been difficult for us to differentiate between painless thyroiditis and lithium associated autoimmune thyroiditis. Treatment with methimazole may have partly affected the change from a hyperthyroid to a euthyroid state in this patient.

1 Jefferson JW. Lithium carbonate-induced hypothyroidism. Its many faces. $\mathcal{f} A M A 1979 ; 242: 271-2$.

2 McDermott MT, Burman KD, Hofeldt FD, Kidd GS. Lithium-associated thyrotoxicosis. $\mathrm{Am} f \mathrm{Med}$ 1986;80 $1245-8$

3 Mizukami Y, Michigishi T, Nonomura A, Nakamura S, Noguchi M, Takazakura E. Histological features of the thyroid gland in a patient with lithium induced thyrotoxicosis. f Clin Pathol 1995;48:582-4.

4 Bocchetta A, Bernardi F, Pedditzi M, Loviselli A, Velluzzi F Martino E, et al. Thyroid abnormalities during lithium treatment. Acta Psychiatr Scand 1991;83:193-8.

5 Lee S, Chow CC, Wing YK, Shek CC. Thyroid abnormalities during chronic lithium treatment in Hong Kong

6 Gittoes NJL, Franklyn JA. Drug-induced thyroid disorders. Drug Saf 1995;13:46-55.

7 LiVolsi VA. Lymphocytes in the thyroid. In: Surgical pathology of the thyroid. Philadelphia: WB Saunders, 1990:68-97. Kontozoglou T, Mambo N. The histopathologic features of lithium-associated thyroiditis. Hum Pathol 1983;14:737-9.

9 Calabrese JR, Gulledge AD, Hahn K, Skwerer R, Kotz M, Schumacher OP, et al. Autoimmune thyroiditis in manic depressive patients treated with lithium. Am $\mathcal{f}$ Psychiatry 1985;142:1318-21.

10 Mizukami Y, Michigishi T, Nonomura A, Nakamura S, Ishizaki T. Pathology of chronic thyroiditis: A new clinically relevant classification. Pathol Annu 1994;29:135-58.
Department of

Pathology, University

of Hong Kong, Queen

Mary Hospital

K Y Lam

Department of Clinical Pathology, Pamela Youde Nethersole Eastern Hospital F Cheung

Department of Medicine, Pamela Youde Nethersole Eastern Hospital L Y C Yam

C H Lee

Department of Diagnostic Radiology,

Pamela Youde

Nethersole Eastern

Hospital

K H Fung

Correspondence to:

Dr King-Yin Lam,

Department of Pathology,

Queen Mary Hospital,

Pokfulam Road, Hong Kong.

Accepted for publication

5 November 1996

\title{
Atypical manifestations in a patient with systemic lupus erythematosus
}

\author{
K Y Lam, F Cheung, L Y C Yam, C H Lee, K H Fung
}

\begin{abstract}
Systemic lupus erythematosus (SLE) is a chronic systemic inflammatory disease associated with the production of various autoantibodies and involvement of multiple organs. Necropsy findings in a 65 year old woman with SLE who had multiple aortic aneurysms and dissections, as well as other unusual manifestations, are described. The case illustrates the occurrence of and the difficulties encountered in the diagnosis of several diseases, namely aortic aneurysm, aortic dissection, acute pancreatitis, and Penicillium marneffei infection.

(F Clin Pathol 1997;50:174-176)
\end{abstract}

Keywords: systemic lupus erythematosus; aneurysm; dissection.

Systemic lupus erythematosus (SLE) is a chronic systemic inflammatory disease associated with the production of various autoantibodies and involvement of multiple organs. We report the necropsy findings in a patient with

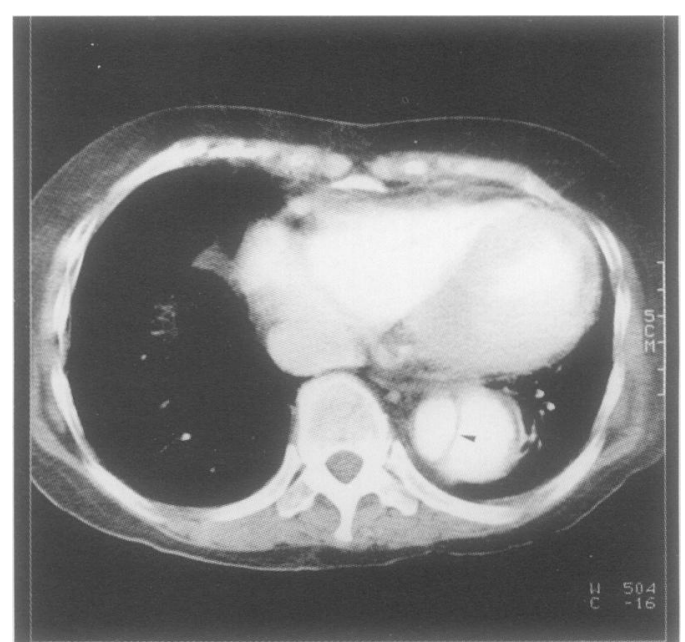

Figure 1 Axial contrast enhanced CT scan of distal thoracic aorta at level of the left ventricle. Presence of an intimal flap (arrowhead) across the aortic lumen at this section would have suggested aortic dissection. This was, however, found to be the undermined edge of a saccular aneurysm. The smaller compartment proved to be the true aortic lumen and the larger one to be the lumen of the saccular aneurysm at necropsy. 
SLE who had multiple aortic aneurysms and dissections, as well as other unusual manifestations.

\section{Case report}

A 65 year old women was admitted to hosptial in June 1994 for management of longstanding hypertension, and investigation of anaemia, proteinuria, and impaired renal function. At this time, the patient's haemoglobin concentration was $66 \mathrm{~g} / \mathrm{l}$, platelet count $105 \times 10^{9} / 1$, urea $15.5 \mathrm{mmol} / \mathrm{l}$, and creatinine $176 \mu \mathrm{mol} / 1$. Antinuclear antibody $(1: 2560$, homogeneous pattern) and anti-double-stranded DNA were detected. A diagnosis of SLE was reached, and the patient was treated with prednisolone $30 \mathrm{mg}$ daily. Azathioprine $(50 \mathrm{mg}$ daily initially, then $100 \mathrm{mg}$ daily) was introduced after two months and prednisolone was tailed down to $20 \mathrm{mg}$ daily.

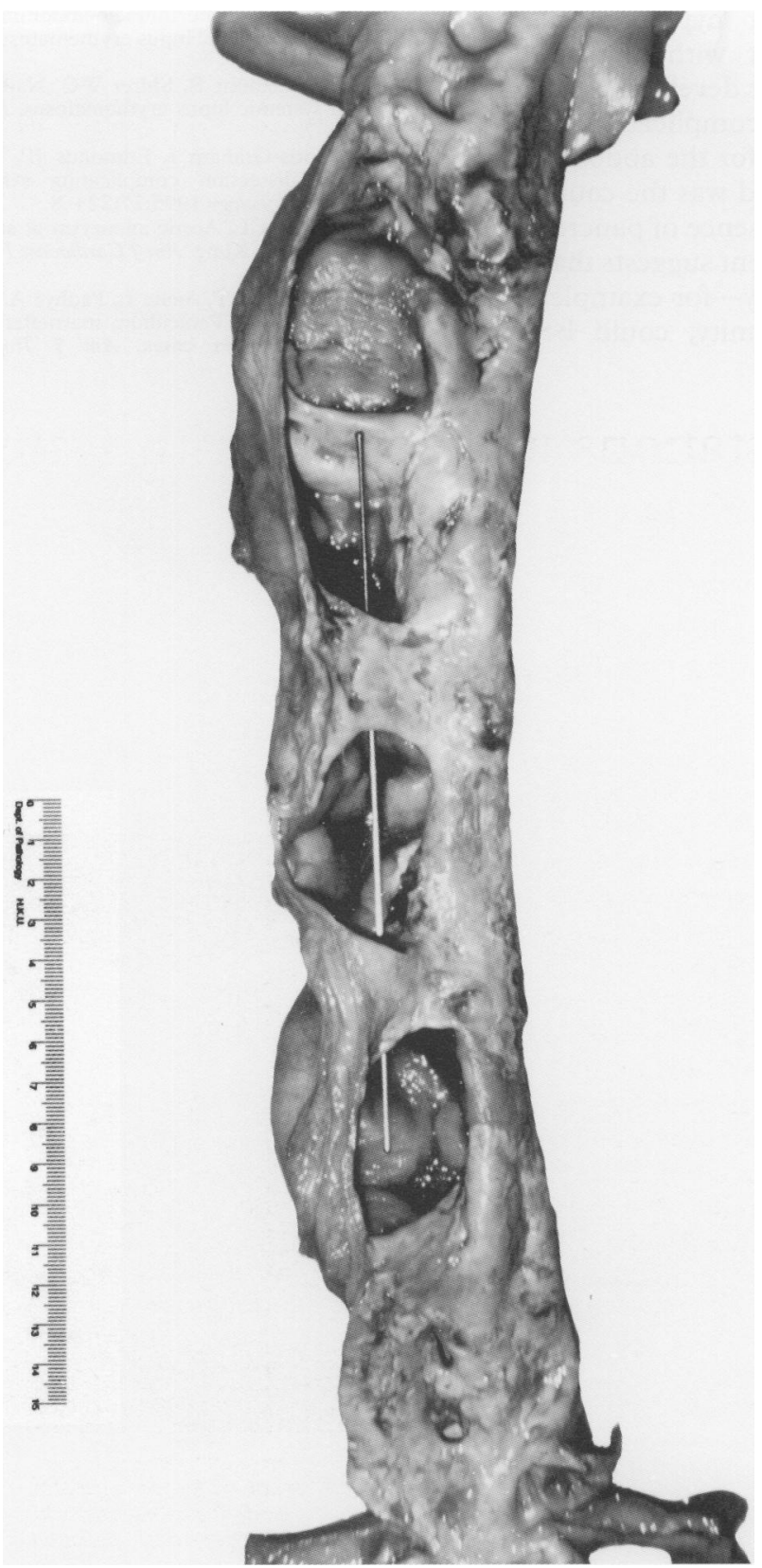

Figure 2 Macroscopic appearance of the aorta at necropsy showing the presence of four saccular aneurysms in the descending aorta. A metal stent was inserted to show the dissections in the aortic wall connecting these aneurysms.
The patient presented again in April 1995 with neutropenic fever, which responded to a two week course of antibiotics. She was re-admitted to hospital in May 1995 with fever and chills. A chest $x$ ray film revealed widened mediastinum and bilateral extensive nodular shadows. Tuberculosis was confirmed after examination of a sputum sample, and treatment was started on the second day after admission. On day 9, the patient complained of colicky abdominal pain and diarrhoea. Acute pancreatitis (amylase $=2159 \mathrm{IU} / \mathrm{l}$ ) complicated by acute renal failure (urea $52.6 \mathrm{mmol} / \mathrm{l}$ and creatinine $683 \mu \mathrm{mol} / \mathrm{l}$ ) was diagnosed on day 12. A contrast enhanced computed tomography (CT) scan was interpreted as type B aortic dissection based on the presence of intimal flap separating two contrast filled compartments (fig 1).

Despite active cardiorespiratory and renal support, the patient went into end stage, multiorgan failure. On day 17, Penicillium marneffei was detected on blood culture. Further active treatment was withheld and the patient died on day 18.

At necropsy, the immediate cause of death was acute pancreatitis; multiple foci of necrosis were noted in the pancreatic parenchyma and the adjacent omentum. Histologically, vasculitis was not observed in the pancreas. There was no evidence of cholelithiasis or other bile duct disorders. Patches of necrosis were seen in the lungs and hilar lymph nodes. Mycobacterial infection was confirmed in these sites by ZiehlNeelsen stain. No signs of infection with $P$ marneffei were noted despite a specific histological search.

Four saccular aneurysms, each around $4 \mathrm{~cm}$ in diameter, were noted in the descending portion of the thoracic aorta (fig 2). Communications were identified between these aneurysms as the aortic wall between them was dissected. Moderate atherosclerosis was seen in the wall. There was no evidence of rupture. The features could be identified by three dimensional reconstruction of the CT scan image after correlation with the necropsy findings. Microscopic examination of the dissections and aneurysms showed cholesterol clefts, fibrosis, myxoid changes, and thrombi in the wall. Vasculitis was not identified.

\section{Discussion}

Aortic aneurysm is a rare complication in patients with SLE; only eight cases have been reported so far. ${ }^{1-8}$ All of them were young patients (age range 26-36 years). Aortic dissections were noted in seven patients (five Daily's type A and two type B) and aortic aneurysms in two patients. One patient had a saccular thoracic aortic aneurysm and a Daily's type A dissection. ${ }^{2}$ The case presented here is unusual as there were multiple aneurysms in addition to the dissections. Also, the combination of Daily's type B dissections and thoracic atherosclerotic aneurysms has never been documented in patients with SLE before.

Vasculitis was detected in the aneurysmal wall in only two patients with SLE. ${ }^{78}$ Thus, the absence of vasculitis does not preclude the 
possibilty that SLE was the cause of the aneurysm. Side effects of treatment with steroids should also be considered in the pathogenesis of the aneurysms. Nevertheless, the contribution of steroids to the development of the aortic lesions is difficult to assess, and aortic aneurysms in an older patient with SLE may still be incidental findings.

Aortic atherosclerotic aneurysm is often present in patients with atherosclerosis and aortic dissecting aneurysm in those with systemic hypertension. Hypertension is a fairly common finding in patients with aortic aneurysm and atherosclerosis is often present in patients with aortic dissection. However, reports describing combined aortic atherosclerotic aneurysm and dissection are rare. ${ }^{29}$ This may be partly related to the lack of necropsy series. Furthermore, the diagnosis of these unusual combinations is difficult, as can be seen from fig 1 . The presence of four saccular aneurysms with intervening dissections is also rare and it is possible that hypertension, atherosclerosis and treatment with steroids might have contributed to their development.

Acute pancreatitis, a rare complication in patients with SLE, accounted for the abdominal pain, acute renal failure and was the cause of death in our patient. The absence of pancreatic vascular lesions in this patient suggests that factors other than vasculopathy-for example, hyperlipidaemia or autoimmunity, could be implicated in the pathogenesis.
Penicillium marneffei is a fungus which is endemic in Southeast Asia. Infection has been reported in both healthy and immunocompromised patients, and once in a patient with SLE. ${ }^{10}$ It was not surprising that $P$ marneffei was not found at necropsy in this patient because the infection may be still in the early phase and the quantity of the fungi may not be sufficient for detection in autolysed necropsy tissue.

1 Bernard GC, Lange RL, Hensley GT. Aortic disease with valvular insufficiency as the principal manifestation of sys-
temic lupus erythematosus. Ann Intern Med 1969;71:81-7.

2 Walts AE, Dubois EL. Acute dissecting aneurysm of the aorta as the fatal event in systemic lupus erythematosus. Am Heart f 1977;93:378-81

3 Okiye SE, Sterioff S, Schaff HV, Engen DE, Zincke H. Acute dissecting aneurysm of the aorta after rena transplantation. $\mathcal{f}$ Urol 1983;129:803-4.

4 Pazirandh $M$, Ziran B. Dissecting aortic aneurysm in a patient with SLE. $\mathcal{F}$ Rheumatol 1988;15:525-7.

5 Lansman SL, Raissi S, Ergin A, Griepp RB. Urgent operation for acute transverse aortic arch dissection. $\mathcal{F}$ Thorac Cardiovas Surg 1989;97:334-41.

6 Dugo M, Liessi G, De Luca M, Arduini R, Susanna F, Cascone C. Dissection of the thoracic-abdominal aorta in young adult with systemic lupus erythematosus. Clin Nephrol 1993;39:349-51.

7 Stehbens WE, Delahunt B, Shirer WC, Naik DK. Aortic aneurysm in systemic lupus erythematosus. Histopathology 1993;22:275-7.

8 Guard RW, Gotis-Graham I, Edmonds JP, Thomas AC. Aortitis with dissection complicating systemic lupus erythematosus. Pathology 1995;27:224-8.

9 Lam AKY, Chan ACL. Aortic aneurysm at autopsy: a five year survey in Hong Kong. Am 7 Cardiovasc Pathol 1992;4: year sur
$31-40$.

10 Jayanetra P, Nitiyanant P, Ajello L, Padhye AA, Lolekha S, Atichartakarn V, et al. Penicillium marneffei in Thailand: report of five human cases. Am $\mathcal{f}$ Trop Med Hyg 1984;33:637-44 